\title{
Hydro-Methanolic Extract of Cornus Mas L. and Blood Glucose, Lipid Profile and Hematological Parameters of Male Rats
}

\author{
Bita Abdollahi ${ }^{1}$; Mehran Mesgari Abbasi ${ }^{1,2,}$; Parvin Zakeri Milani ${ }^{3}$; Ashraf Sadat Nourdadgar \\ ${ }^{4} ;$ Seyyed Mehdi Banan Khojasteh ${ }^{5}$;Vahid Nejati ${ }^{6}$ \\ ${ }^{1}$ Drug Applied Research Center, Tabriz University of Medical Sciences, Tabriz, IR Iran \\ ${ }^{2}$ Student Research Committee, Tabriz University of Medical Sciences, Tabriz, IR Iran \\ 3 Liver and Gastrointestinal Research Center, Tabriz University of Medical Sciences, Tabriz, IR Iran \\ ${ }_{5}^{4}$ Medical Education Research Center, Tabriz University of Medical Sciences, Tabriz, IR Iran \\ 5 Medical Education Research Center, Tabriz University of Medical Sciences, Tabriz, IR Iran \\ ${ }_{6}$ Department of Natural Sciences, Faculty of Natural
Faculty of Science, Urmia University, Urmia, IR Iran \\ *Corresponding Author: Mehran Mesgari Abbasi, Student Research Committee, Tabriz University of Medical Sciences, Tabriz, IR Iran. Tel:+98-9141168681, E-mail: mesgarim@tbzmed.ac.ir
}

Received: January 23, 2014; Revised: March 19, 2014; Accepted: April 1, 2014

Background: Cormus mas L, an olive-shaped red-colored single-seeded fruit, is used in traditional medicine in different parts of Europe and Asia.

Objectives: In the present study, 40 male Wistar rats were randomly divided into five groups, and the effects of 21 days of intraperitoneally (IP) administration of 50, 200 and $400 \mathrm{mg} / \mathrm{kg}$ body weight of C. mas hydro-methanolic extract on the rats hematological and biochemical parameters were investigated. The experimental study was carried out in Tabriz, Iran.

Materials and Methods: The hematology and biochemical tests were performed by the Technicon H1 Hematology Analyzer and enzymatic methods, respectively.

Results: The results indicated that all doses of the extract caused significant $(\mathrm{P}<0.05)$ decreases in the hemoglobin distribution width (HDW) $(2.3 \pm 0.2$ vs. $2.5 \pm 0.2, \mathrm{P}=0.049)$ and platelet distribution width (PDW) $(56.5 \pm 1.8$ vs. $63.9 \pm 3.6, \mathrm{P}=0.001)$ of the treated groups vs. control group, whereas only high doses caused significant elevation in the mean corpuscular hemoglobin concentration (MCHC) (30.3 \pm 0.8 vs. $28.6 \pm 0.6, \mathrm{P}=0.047)$, mean platelet volume (MPV) $(5.0 \pm 0.6$ vs. $4.1 \pm 0.3, \mathrm{P}=0.002)$, total platelet mass (PCT) $(0.33 \pm 0.07 \mathrm{vs}$. $0.26 \pm$ $0.01, \mathrm{P}=0.050)$, and significant decrease in the red cell distribution width $(\mathrm{RDW})(13.8 \pm 0.4 \mathrm{vs} .14 .7 \pm 1.3, \mathrm{P}=0.048)$ of the treated groups vs. control group.

Conclusions: Decreasing effect of the extract on platelet activity might classify it as an alternative for antiplatelet therapy in cardiovascular diseases (CVD). The results of this study suggested that further investigations with higher doses of $C$. mas fruit extract are necessary to obtain significant protective and nonprotective changes in hematological and biochemical parameters.

Keywords:Cornus; Biological Markers; Hematologic Tests; Blood Glucose

\section{Background}

Cornelian cherry (Cormus mas L.) is the most important fruit from the 40 species of the Cornaceae family (1). C. mas $L$. is a species of dogwood, native to southern Europe and Asia (2-4). In Iran, cornelian cherry trees are spread in the west parts of the country (East Azerbaijan and Qazvin provinces) $(1,5)$. It is a medium-to-large deciduous shrub or small tree that grows up to 5-12 m. Cornelian cherries are typically olive-shaped single-seeded fruits, and 10-23 $\mathrm{mm}$ long, originating from an inferior ovary. They are typically red, but can also be found in pink and yellow in general, and are sweet-sour $(1,4,6,7)$. It is worth noting that different products are produced from the cornelian cherry. The fruits not only are consumed fresh but also used to produce jam, stewed fruit, compote, syrup, and several types of soft drinks. In Iran, cornelian cherry fruits are consumed freshly, dried whole, and pickled like olives (1).
There are some investigations regarding the physical and chemical properties of cornelian cherry fruits (3, $8,9)$. Fresh cornelian cherry fruits, containing twice as much ascorbic acid (vitamin $\mathrm{C}$ ) as oranges, show their potential as a food additive $(1,4,6,7)$. These fruits are also rich in sugar, organic acids, tannins, anthocyanins, phenols, and other antioxidants $(8,10,11)$. Compared to other juices obtained from plum, pear and apple, cornelian cherry juice contains high levels of Calcium, reaching 10 folds higher (323 mg/L) than other juices (14-77 mg/L). Furthermore, cornelian cherries have high contents of $\mathrm{K}$ and $\mathrm{Mg}$, but are low in $\mathrm{Na}$ and other essential minerals (Cu, Mn, Fe, and $\mathrm{Zn}$ ); their levels of toxic elements are also negligible (9-14). In Iranian, Caucasus and Central Asia traditional medicine, cornelian cherry was being used for more than 1000 years $(11,15,16)$. Galenicals are 
made from leaves and flowers, and fruits have been used to treat sore throat, digestion problems, measles, chickenpox, anemia, rickets, and liver (hepatitis A) and kidney (pyelonephritis) diseases in traditional and conventional medicine $(15,17,18)$. The juice and the evaporated juice of the fruit are used against diabetes as well $(19,20)$. Besides, the galenicals from leaves, dried fruits powder, ground, and dried drupes are widely used in diarrhea and hemorrhoids treatments $(15,17)$. The fruit flesh and the seed oil are successfully used for curing difficult-to-heal wounds, stomach ulcers, and colitis $(15,17,18,21)$. Moreover, several cornus spp. fruits are used to improve liver and kidney functions. It was also reported to have antibacterial, antihistamine, antiallergic, antimicrobial, and antimalarial activities (3). In this respect, the astringent property of this fruit is a good treatment for bowel complaints and fevers, and also used in cholera treatment (3). Scholars in the former Soviet Union noted that the fruit flesh and the seed oil were also useful for recovery and regeneration of damaged inner and outer epidermic tissues (skin and mycoderms) $(15,17,18)$.

Furthermore, C. mas, a medicinal plant, was mentioned for treatment of circulation disorders and blood dilution in traditional medicine in Iran. However, this plant has not been subjected to systematic investigation to assess its hematological and biochemical effects. Reviewers believe that the researched to date have had poor qualities, and larger and more rigorous trials are needed to investigate the possible adverse effects associated with excessive polyphenol intake by consuming polyphenol-rich fruits; currently, lack of knowledge about the polyphenol safety, suggests that its levels should not exceed a normal diet amount (22). Moreover, hematological parameters assessment can be used to determine the extent of deleterious effects of the extracts on the animal blood. It can also be used to explain the blood-related functions of the plant extract or its products (23).

\section{Objectives}

Aim of the present study was to investigate some hematological and biochemical effects of C. mas fruit extract on healthy male rats.

\section{Materials and Methods}

\subsection{Plant Ingredients and Extraction}

The C. mas fruits were obtained from the suburbs of Kaleibar (East Azarbaijan, Iran). The fruits were washed and their seeds were removed. The fruit plant parts were airdried, protected from direct sunlight, and then turned into a coarse powder. Afterwards, $500 \mathrm{~g}$ of the powder was extracted by methanol and water mixture (7:3) at 25 $\pm 2^{\circ} \mathrm{C}$. The mixture was then filtered and the solvent was completely removed by a rotary vacuum evaporator at $50^{\circ} \mathrm{C}$. Finally, the C. mas fruits extract was frozen, dried and stored until use.

\subsection{Animals}

In this experimental study, 40 male Wistar rats, weighing $220 \pm 20 \mathrm{~g}$, were used. The animals were housed in polycarbonate standard cages in a temperature-controlled room $\left(22 \pm 2^{\circ} \mathrm{C}\right)$ under $12 / 12$ hours of light/dark cycles for one week, before and during the experiments. Next, the animals were provided by a standard rat pellet diet and clean drinking water ad libitum. All the ethical and humanity considerations as well as euthanasia of the animals were considered and performed during the experiments.

\subsection{Procedures}

The sample size was determined according to the previous similar animal studies (24-27). Using the Randlist software, the animals were randomly divided into five groups (eight animals in each group) as follows:

1. Group I served as the normal control and received a normal diet without any injection.

2. Group II served as the placebo control and intraperitoneally (IP) received a normal saline, daily for three weeks.

3. Group III-V served as the treatment groups. They IP received the C. mas fruit extract (CMFE) at the doses of 50, 200 and $400 \mathrm{mg} / \mathrm{kg}$ of body weight (BW), daily for three weeks.

At the end of the interventional period, the blood samples were taken from each animal by cardiac puncture. Samples were immediately transferred into tubes together with ethylenediaminetetraacetic acid (EDTA) as the hematology anticoagulant to analyze and clot the tubes for biochemical analyses. All the animals experiments were approved by the Research Ethics Committee of Tabriz University of Medical Sciences (ethical approval code: 5-4-1171, date: 4 May 2013) and performed according to the Helsinki's humanity research declaration.

\subsection{Hematological Analyses}

The hematology parameters were explored by the Technicon-H1 (Bayer) hematology analyzer. Technicon H-1 apparatuses are discrete analyzers that perform complete blood and platelet counts, as well as leukocyte differential count. The instrument has a tungsten halogen light source, a cytometer for leukocyte peroxidase analysis, and a helium-neon red laser for RBC/platelet and basophil determinations. In addition, within the cell flow, the cells were classified one by one based on size and cytochemical peroxidase reaction. The instrument was calibrated and validated using several calibrators before testing the samples. The results of the analyzer were checked by microscopic analyses of the blood smears, stained with May-Grünwald and Giemsa-Romanowski. 
Abdollahi B et al.

\subsection{Biochemical Analyses}

The clotted blood samples were centrifuged at $2000 \mathrm{~g}$, and the blood serums were separated and placed in $-70^{\circ} \mathrm{C}$ freezer until performing the tests. Afterward, the blood glucose, triglyceride, cholesterol, low density lipoprotein (LDL), and high density lipoprotein (HDL) were determined by the enzymatic methods (Parsazmun, Iran) with the automated Abbott, Alcyon 300 biochemistry analyzer (USA). The instrument was calibrated and validated using several calibrators before testing the samples.

\subsection{Data Analyses}

Before presenting the results, Kolmogrof-smirnof test was performed with Q-Q chart for surveying the normality. In addition, results of Levene test showed equality of variances of the groups. All the results were expressed as mean \pm SD. One-way analysis of variance (ANOVA) was used to compare different parameters between the groups, followed by multiple comparisons with the Tukey post-hoc test. P value $<0.05$ was considered significant.

\section{Results}

There were no significant differences in the red blood cell (RBC) count, hemoglobin (Hb), packed cell volume (PCV), mean corpuscular volume (MCV), and mean corpuscular hemoglobin $(\mathrm{MCH})$ between the treated and control groups (Table 1). However, a significant increase $(\mathrm{P}=0.047)$ in the mean corpuscular hemoglobin concentration (MCHC) was found in the C. mas high dose (400 $\mathrm{mg} / \mathrm{kg} \mathrm{BW}$ ) treated group in comparison with the control group (Table 1). There were also significant decreases in red cell distribution width (RDW) in the groups with 200 and $400 \mathrm{mg} / \mathrm{kg} \mathrm{BW}$. Besides, there were significant decreases $(\mathrm{P}=0.049)$ in hemoglobin distribution width (HDW) in the groups treated with 50, 200, and $400 \mathrm{mg} /$ $\mathrm{kg}$ BW C. mas, compared with the control groups (Table 1). Although results of the present study showed no signifi- cant differences between many of the RBC and hemoglobin-dependent parameters, Table 1 shows that treatment with the high-dose (400 mg/kg BW) CMFE caused a significant increase $(\mathrm{P}<0.05)$ in MCHC. That is due to the nonsignificant decrease of MCV and increase of $\mathrm{MCH}$ in this group in comparison with the control group. MCHC might be expected to increase in the treated rats with higher doses of CMFE; it is suggested to be studied in future. The results also indicated that CMFE caused a decrease in RDW that was significant $(P=0.048)$ in 200 and $400 \mathrm{mg} / \mathrm{kg}$ BW doses. RDW is the the frequency distribution curve width of the RBC volume (one SD) divided by the mean RBC volume. Therefore, decrease of RDW meant that the RBCs did not vary much in size (28); it was probably resulted from the decrease (nonsignificant) of MCV. In addition, there was a significant decrease $(P=0.049)$ in HDW in the treated groups in comparison with the control groups. This meant that the hemoglobin contents of the RBCs did not vary much, probably resulted from nonsignificant increase of $\mathrm{MCH}$. Significant increase of MCHC and decrease of RDW were in agreement with the effects of antioxidant-rich natural compounds on hematopoiesis (29-32). The results showed that treatment with $400 \mathrm{mg} / \mathrm{kg}$ BW of CMFE caused a significant increase ( $P$ $=0.002)$ in the mean platelet volume (MPV) and total platelet mass (PCT). There was also significant increase in MPV in the group treated with $200 \mathrm{mg} / \mathrm{kg}$ BW of CMFE (Table 2). A significant decrease $(P=0.001)$ in the platelet distribution width (PDW) was also found in the groups treated with 50, 200, and $400 \mathrm{mg} / \mathrm{kg}$ BW of CMFE (Table 2). The high dose ( $400 \mathrm{mg} / \mathrm{kg}$ BW) caused nonsignificant increase in the platelet count as well. The abovementioned changes in the platelet-related parameters suggested platelet activity inhibition without bone marrow suppression in the treated groups in comparison with the control groups. MPV and PDW increased during the platelet activation. PDW is a more specific marker of the platelet activation, since it does not increase during the simple platelet swelling (33). In this regard, increased

\begin{tabular}{|c|c|c|c|c|c|c|}
\hline Parameter/Group & $\begin{array}{l}\text { Control } \\
\text { (Normal) }\end{array}$ & $\begin{array}{l}\text { Control } \\
\text { (Placebo) }\end{array}$ & $\begin{array}{c}\text { C. mas } \\
(50 \mathrm{mg} / \mathrm{kg} \mathrm{BW})\end{array}$ & $\begin{array}{c}\text { C. mas } \\
(200 \mathrm{mg} / \mathrm{kg} \mathrm{BW})\end{array}$ & $\begin{array}{c}\text { C. mas } \\
(400 \mathrm{mg} / \mathrm{kg} \mathrm{BW})\end{array}$ & P Value \\
\hline $\mathrm{RBC}, \mathbf{1 0}^{12} / \mathrm{L}$ & $7.8 \pm 0.6$ & $7.8 \pm 0.6$ & $7.6 \pm 0.3$ & $7.7 \pm 0.4$ & $7.9 \pm 0.5$ & 0.582 \\
\hline $\mathrm{Hb}, \mathrm{g} / \mathrm{dL}$ & $13.0 \pm 0.5$ & $13.1 \pm 0.8$ & $13.1 \pm 0.9$ & $12.9 \pm 0.4$ & $13.5 \pm 0.9$ & 0.407 \\
\hline PCV, \% & $45.6 \pm 2.1$ & $45.4 \pm 2.1$ & $44.1 \pm 2.1$ & $43.4 \pm 2.0$ & $46.3 \pm 5.6$ & 0.364 \\
\hline MCV, fL & $58.1 \pm 2.3$ & $58.0 \pm 2.4$ & $58.6 \pm 2.6$ & $56.4 \pm 1.5$ & $56.7 \pm 1.7$ & 0.163 \\
\hline MCH,pg & $16.6 \pm 0.9$ & $16.6 \pm 0.8$ & $17.3 \pm 0.9$ & $16.8 \pm 0.7$ & $17.2 \pm 0.5$ & 0.339 \\
\hline MCHC, g/dL & $28.6 \pm 0.6$ & $28.8 \pm 0.9$ & $29.6 \pm 1.3$ & $29.7 \pm 1.3$ & $30.3 \pm 0.8$ & 0.047 \\
\hline RDW, \% & $14.7 \pm 1.3$ & $14.7 \pm 0.9$ & $13.9 \pm 0.7$ & $13.9 \pm 0.5$ & $13.8 \pm 0.4$ & 0.048 \\
\hline HDW, g/dL & $2.5 \pm 0.2$ & $2.5 \pm 0.2$ & $2.3 \pm 0.1$ & $2.3 \pm 0.2$ & $2.3 \pm 0.1$ & 0.049 \\
\hline
\end{tabular}

\footnotetext{
a Data are expressed as mean $\pm \mathrm{SD}$, the parameters with significant differences $(\mathrm{P}<0.05)$.
b Abbreviations: Hb, hemoglobin; $\mathrm{MCH}$, mean corpuscular hemoglobin; $\mathrm{MCHC}$, mean corpuscular hemoglobin concentration; MCV; mean corpuscular volume; RBC, red blood cell count; PCV, packed cell volume; RDW, red cell distribution width.
} 
Abdollahi B et al.

MPV indicated a large number of larger and younger platelets in the blood, probably due to the bone marrow rapid production and release of the platelets into the blood circulation. Besides, decreased PDW indicated uniformity in the size of platelets and inactivation of the platelets, which was in agreement with traditional medicine specialists' believes about the cardiovascular protective effects of $C$. mas. It is evident that antioxidants reduce the platelet activity through stimulation of prostacyclin synthesis and scavenging the synthesisinhibiting peroxides. The experimental and clinical evidences supporting this theory are inconclusive (34, 35). Furthermore, recent studies have shown that polyphenols such as catechin and quercetin, stop NADPH oxidase enzyme (present in platelets). Therefore, inhibiting the production of $\mathrm{O2}^{-}$and increasing the biological power of NO consequently regulate glycoprotein pine receptors on platelet membrane surface (GPIIbIIIa), that in turn inhibits platelets' activation and their adherence during inflammation and thrombosis processes (36). As a result, it is probable that the antioxidant compounds in C. mas L. fruits, including vitamins, anthocyanins (37), and phenolic compounds, prevent the platelet activity. Platelet hyperactivity is one of the well-identified risk factors for cardiovascular disorders (CVD) developments and complications $(38,39)$. Moreover, antiplatelet therapies are associated with resistance; they were reported to have side effects and contraindications which were prompted for investigations of natural products as alternatives for prevention and treatment of CVD (40-42). Treating with C. mas may be a good choice for this purpose, but more investigations and trials are necessary.

The results showed no significant changes $(\mathrm{P}=0.279)$ in white blood cells (WBC), absolute neutrophils (NEUT), lymphocytes (LYMP), monocytes (MONO), eosinophils (EOS) and basophils (BASO) counts, differential leukocyte percent, large unstained cells (LUC), myeloperoxidase index (MPXI), and lobularity index (LI) between the treated and control groups. There were not significant differences between the results of leukocytes related parameters (Table 3), whereas Table 3 shows mild con- tinuous increases in the percentages, absolute counts of the eosinophils, and LUC, as well as mild decreases in the LI between the groups from low to high doses. In addition, significant increases in the eosinophils and LUC, and significant decreases in the LI, treating with higher doses than the ones used in this study might be expected. Moreover, increase in the eosinophils may be due to reduction in the eosinophil apoptosis. Eosinophil apoptosis is mediated by stimulators of cellular oxidative metabolisms and inhibited by antioxidants (43). The results suggest that antioxidant properties of CMFE may inhibit the eosinophil apoptosis. LUCs are large cells without myeloperoxidase (MPO). Large atypical lymphocytes, plasma cells, and some blasts are characterized as LUCs. The MPO inhibition, interaction activity of the polyphenols, and other antioxidants were also reported by some researchers $(44,45)$. Further investigations with different and higher doses of CMFE are necessary for discussing its effect on the MPO activity and the granules.

The results indicated no significant differences $(\mathrm{P}=$ 0.917) in the glucose, cholesterol, LDL, HDL, and triglyceride amounts, between the treated and the nontreated groups (Table 4). However, a mild decrease and a mild increase (but not significant) in the total cholesterol and HDL were found, respectively; it was based on findings of some previous studies (24). There were some reports about hypolipidemic effects of natural products anthocyanins (25). Higher doses of CMFE were expected to cause significant decrease and increase in cholesterol and HDL, respectively; it is suggested for future studies.

Results of some previous studies showed that C. mas had antidiabetic effects and can improve the pancreas damage caused by free radicals in diabetic rats (26). However, there was a controversy about its hypoglycemic effect on healthy animal models (27). In addition, there were some interventional factors, probably interfered our detected parameters; one of them was nutritional deficiencies of rats. We used commercial laboratory animal food in our study. The food analysis report did not declare many microelement and vitamin quantities.

\begin{tabular}{|c|c|c|c|c|c|c|}
\hline Parameter/Group & Control (Normal) & Control (Placebo) & $\begin{array}{c}\text { C. mas } \\
(50 \mathrm{mg} / \mathrm{kg} \mathrm{BW})\end{array}$ & $\begin{array}{c}\text { C. mas } \\
(200 \mathrm{mg} / \mathrm{kg} \mathrm{BW})\end{array}$ & $\begin{array}{c}\text { C. mas } \\
(400 \mathrm{mg} / \mathrm{kg} \mathrm{BW})\end{array}$ & PValue \\
\hline PLT, $10^{9} / \mathrm{L}$ & $545.3 \pm 38.5$ & $531.1 \pm 88.2$ & $514.7 \pm 123.3$ & $545.3 \pm 124.9$ & $607.5 \pm 124.5$ & 0.449 \\
\hline MPV, fL & $4.1 \pm 0.3$ & $4.1 \pm 0.3$ & $4.2 \pm 0.3$ & $4.6 \pm 0.5$ & $5.0 \pm 0.6$ & 0.002 \\
\hline PDW, \% & $63.9 \pm 3.6$ & $63.6 \pm 3.2$ & $62.4 \pm 1.0$ & $60.3 \pm 4.4$ & $56.5 \pm 1.8$ & 0.001 \\
\hline PCT, \% & $0.26 \pm 0.01$ & $0.24 \pm 0.02$ & $0.24 \pm 0.05$ & $0.29 \pm 0.07$ & $0.33 \pm 0.07$ & 0.050 \\
\hline
\end{tabular}

${ }^{\mathrm{a}}$ Abbreviations: BW, body weight; C. mas, Cornus mas; MPV; mean platelet volume, PCT; total platelet mass, PDW; platelet distribution width.

$\mathrm{b}$ Data are expressed as mean \pm SD, the parameters with significant differences $(\mathrm{P}<0.05)$. 
Abdollahi B et al.

\begin{tabular}{|c|c|c|c|c|c|c|}
\hline Parameter/Group & Control (Normal) & Control (Placebo) & $\begin{array}{c}\text { C. mas } \\
(50 \mathrm{mg} / \mathrm{kg} \mathrm{BW})\end{array}$ & $\begin{array}{c}\text { C. mas } \\
(200 \mathrm{mg} / \mathrm{kg} \mathrm{BW})\end{array}$ & $\begin{array}{c}\text { C. mas } \\
(400 \mathrm{mg} / \mathrm{kg} \mathrm{BW})\end{array}$ & PValue \\
\hline WBC, $\times 10^{9} / L$ & $9.86 \pm 2.13$ & $11.26 \pm 2.22$ & $11.15 \pm 2.44$ & $9.73 \pm 3.34$ & $13.11 \pm 5.58$ & 0.279 \\
\hline NEUT, $\times 10^{9} / \mathrm{L}$ & $1.36 \pm 0.65$ & $1.36 \pm 0.65$ & $1.32 \pm 0.64$ & $1.79 \pm 0.86$ & $1.86 \pm 0.92$ & 0.762 \\
\hline NEUT, \% & $12.8 \pm 6.3$ & $12.5 \pm 5.8$ & $11.3 \pm 5.5$ & $18.5 \pm 9.2$ & $13.6 \pm 6.3$ & 0.400 \\
\hline LYMP, $\times 10^{9} / L$ & $6.29 \pm 1.33$ & $7.84 \pm 1.55$ & $7.75 \pm 1.67$ & $6.00 \pm 2.77$ & $8.67 \pm 3.88$ & 0.206 \\
\hline LYMP, \% & $64.0 \pm 6.2$ & $63.9 \pm 8.5$ & $69.6 \pm 4.5$ & $61.1 \pm 11.5$ & $65.2 \pm 10.4$ & 0.389 \\
\hline MONO, $\times 10^{9} / \mathrm{L}$ & $1.36 \pm 0.56$ & $1.29 \pm 0.52$ & $1.16 \pm 0.48$ & $1.04 \pm 0.31$ & $1.34 \pm 0.66$ & 0.606 \\
\hline MONO,\% & $14.9 \pm 7.2$ & $12.5 \pm 6.1$ & $11.1 \pm 5.3$ & $11.3 \pm 4.0$ & $11.3 \pm 5.4$ & 0.587 \\
\hline $\mathrm{EOS}, \times 10^{9} / \mathrm{L}$ & $0.16 \pm 0.08$ & $0.10 \pm 0.05$ & $0.11 \pm 0.05$ & $0.13 \pm 0.06$ & $0.20 \pm 0.10$ & 0.785 \\
\hline EOS, \% & $1.45 \pm 0.72$ & $0.95 \pm 0.47$ & $0.98 \pm 0.48$ & $1.53 \pm 0.76$ & $1.65 \pm 0.81$ & 0.868 \\
\hline BASO, $\times 10^{9} / \mathrm{L}$ & $0.11 \pm 0.04$ & $0.15 \pm 0.05$ & $0.11 \pm 0.05$ & $0.08 \pm 0.06$ & $0.18 \pm 0.88$ & 0.084 \\
\hline BASO, \% & $1.21 \pm 0.60$ & $1.20 \pm 0.52$ & $0.95 \pm 0.19$ & $0.83 \pm 0.30$ & $1.33 \pm 0.54$ & 0.189 \\
\hline LUC, $\times 10^{9} / \mathrm{L}$ & $0.59 \pm 0.29$ & $0.71 \pm 0.34$ & $0.68 \pm 0.34$ & $0.66 \pm 0.32$ & $0.83 \pm 0.40$ & 0.651 \\
\hline LUC, \% & $5.91 \pm 2.10$ & $5.81 \pm 2.33$ & $6.10 \pm 2.40$ & $6.73 \pm 3.32$ & $14.65 \pm 7.20$ & 0.531 \\
\hline LI & $1.24 \pm 0.05$ & $1.24 \pm 0.05$ & $1.23 \pm 0.06$ & $1.22 \pm 0.04$ & $1.18 \pm 0.05$ & 0.199 \\
\hline MPXI & $-40.3 \pm 3.8$ & $-40.2 \pm 3.8$ & $-40.2 \pm 4.6$ & $-38.8 \pm 3.2$ & $-39.0 \pm 3.2$ & 0.254 \\
\hline
\end{tabular}

a Abbreviations: BW, body weight; BASO, basophils; C. mas, Cornus mas; EOS, eosinophils; LYMP, lymphocytes; LUC, large unstained cells; LI, lobularity index; MONO, the monocytes; MPXI, the myeloperoxidase index; NEUT, the absolute neutrophils; WBC, white Blood Cell.

$\mathrm{b}$ Data are expressed as mean $\pm \mathrm{SD}$, the parameters with significant differences $(\mathrm{P}<0.05)$.

\begin{tabular}{|c|c|c|c|c|c|c|}
\hline Parameter/Group & Control (Normal) & Control (Placebo) & $\begin{array}{c}\text { C. mas } \\
(50 \mathrm{mg} / \mathrm{kg} \mathrm{BW})\end{array}$ & $\begin{array}{c}\text { C. mas } \\
(200 \mathrm{mg} / \mathrm{kg} \mathrm{BW})\end{array}$ & $\begin{array}{c}\text { C. mas } \\
(400 \mathrm{mg} / \mathrm{kg} \mathrm{BW})\end{array}$ & P Value \\
\hline Glucose, mg/dL & $151.3 \pm 48.9$ & $152.5 \pm 37.5$ & $151.3 \pm 35.3$ & $167.4 \pm 82.5$ & $150.3 \pm 12.0$ & 0.917 \\
\hline $\begin{array}{l}\text { Cholesterol, mg/ } \\
\text { dL }\end{array}$ & $73.3 \pm 18.0$ & $72.4 \pm 9.8$ & $64.7 \pm 6.4$ & $64.4 \pm 23.5$ & $65.4 \pm 9.1$ & 0.719 \\
\hline HDL, mg/dL & $25.3 \pm 6.8$ & $25.5 \pm 6.4$ & $27.3 \pm 3.9$ & $27.6 \pm 5.1$ & $26.7 \pm 7.0$ & 0.902 \\
\hline LDL, $\mathrm{mg} / \mathrm{dL}$ & $30.0 \pm 4.2$ & $29.3 \pm 4.3$ & $30.0 \pm 3.6$ & $32.5 \pm 3.5$ & $26.7 \pm 3.5$ & 0.872 \\
\hline $\begin{array}{l}\text { Triglyceride, mg/ } \\
\text { dL }\end{array}$ & $75.8 \pm 16.6$ & $84.6 \pm 16.2$ & $63.8 \pm 10.5$ & $74.6 \pm 19.7$ & $78.9 \pm 12.0$ & 0.320 \\
\hline
\end{tabular}

\section{Discussion}

Results of the present study indicated that all doses of C. mas hydro-methanolic extract caused significant decreases in HDW and PDW, whereas only high doses (200 and 400) caused significant elevation in MCHC, MPV and PCT, and significant decrease in RDW. Furthermore, trend of the results suggested the probability of $C$. mas usage as prophylactic and alternative therapy for CVD. However, further investigations with higher doses of CMFE are necessary to obtain significant protective and nonprotective changes in hematological and biochemical parameters.

\section{Acknowledgements}

The authors thank the heads and staffs of the Student Research committee and Drug Applied Research Center for their financial and technical supports.

\section{Authors' Contribution}

Study concept and design: Banan Khojasteh, Vahid Nejati; animal procedures and sampling: Abdollahi, Mesgari Abbasi, Nourdadgar; analysis and interpretation of data: Mesgari Abbasi, Zakeri Milani; drafting of the manuscript: Mesgari Abbasi, critical revision of the manuscript for important intellectual content: Zakeri Milani, statistical analysis: Mesgari Abbasi, Abdollahi; study supervision: Mesgari Abbasi.

\section{Financial Disclosure}

Authors had no financial interests related to the materials in the manuscript. 


\section{Funding/Support}

This study was supported by a grant from the Student Research Committee, Tabriz University of Medical Sciences, Tabriz, Iran

\section{References}

1. Hassanpour H, Hamidoghli Y, Hajilo J, Adlipour M. Antioxidant capacity and phytochemical properties of cornelian cherry (Cornus mas L.) genotypes in Iran. Scientia Horticulturae. 2011;129(3):459-63.

2. Güleryüz M, Bolat I, Pirlak L. Selection of table cornelian cherry (Cornus mas L.) types in Çoruh Valley.J Agric. 1998;22:357-64.

3. Vareed SK, Reddy MK, Schutzki RE, Nair MG. Anthocyanins in Cornus alternifolia, Cornus controversa, Cornus kousa and Cornus florida fruits with health benefits. Life Sci. 2006;78(7):777-84 .

4. Koyuncu T, Tosun İ, PinarY. Drying characteristics and heat energy requirement of cornelian cherry fruits (Cornus mas L.). J Food Engine. 2007;78(2):735-9.

5. Hassanpour H, Hamidoghli Y, Samizadeh H. Some fruit characteristics of Iranian cornelian cherries (Cornus mas L.). Not Bot Hort Agrobot. 2012;40(1):247-52.

6. Demir F, Hakki Kalyoncu İ. Some nutritional, pomological and physical properties of cornelian cherry (Cornus mas L.). J Food Engine. 2003;60(3):335-41

7. Hassanpour H, Hamidoghli Y, Samizadeh H. Estimation of genetic diversity in some Iranian cornelian cherries (Cornus mas L.) accessions using ISSR markers. Biochem System Ecol. 2013;48:257-62.

8. Rop O, Mlcek J, Kramarova D, Jurikova T. Selected cultivars of Cornelian cherry (Cornus mas L.) as a new food source for human nutrition. Afr J Biotechnol. 2010;9(8):1205-10.

9. Tural S, Koca I. Physico-chemical and antioxidant properties of cornelian cherry fruits (Cornus mas L.) grown in Turkey. Scientia Horticulturae. 2008;116(4):362-6.

10. Yilmaz KU, Ercisli S, Zengin Y, Sengul M, Kafkas EY. Preliminary characterisation of cornelian cherry(Cornus mas L.) genotypes for their physico-chemical properties. Food Chem. 2009;114(2):408-12.

11. Narimani-Rad M, Zendehdel M, Abdollahi B, Lotfi A, Mesgari Abbasi.. Cornelian cherry (Cornus mas L.) Extract affects Glycemic status in Wistar rats. Bull Env Pharmacol Life Sci. 2013;2(9):48-50.

12. Marinova D, Ribarova F, Atanassova M. Total phenolics and total flavonoids in bulgarian fruits and vegetables. J Univ Chem Technol Metall. 2005;40:255-60.

13. Seeram NP, Schutzki R, Chandra A, Nair MG. Characterization, quantification, and bioactivities of anthocyanins in Cornus species. J Agric Food Chem. 2002;50(9):2519-23.

14. Juranović Cindrić I, Zeiner M, Krpetić M, Stingeder G. ICP-AES determination of minor and major elements in Cornelian cherry (Cornus mas L.) after microwave assisted digestion. Microchemical J. 2012;105:72-6.

15. Asadov S, Ibrahimov Z, Sadikhova S. Zoghal (Cornus mas L.) Elm.Turkish;1990.

16. Efendiyev IK. History of Medicine in Azerbaijan from Ancient Times to the 19th Century. Izd AN 1964.Baku (in Russian).

17. Damirov I, Prilipko L, Shukurov D, Kerimov J. Medicinal Plants of Azerbaijan. Maarif.Baku(in Russian); 1983.

18. Tzitzin N, Anichkov C, Itzkov N. Atlas of Medicinal Plants of USSR Gosmed. Izd 1963.Moscow (in Russian).

19. Jayaprakasam B, Vareed SK, Olson LK, Nair MG. Insulin secretion by bioactive anthocyanins and anthocyanidins present in fruits. $J$ Agric Food Chem. 2005;53(1):28-31.

20. Sokolov S, Zamotayev I. Directory of Medicinal Plants. Medicina; 1985.Moscow (in Russian)

21. Lewis WH, Elvin-Lewis MPF. Medical Botany.New York: John Wiley and Sons, Inc; 1977.

22. Habauzit V, Morand C. Evidence for a protective effect of polyphenols-containing foods on cardiovascular health: an update for clinicians. Ther Adv Chronic Dis. 2012;3(2):87-106

23. Yakubu MT, Akanji MA, Oladiji AT. Aphrodisiac potentials of the aqueous extract of Fadogia agrestis (Schweinf. Ex Hiern) stem in male albino rats. Asian J Androl. 2005;7(4):399-404.

24. Mirbadalzade R, Shirdel Z. Anti-hyperglycemic and anti-hyperlip- idemic of hydromethanolic extract of Cornus mas. In diabetic rats and it's comparison with Glibenclamide. Iran J of diabet and lipid disorders. 2010;9(4):335-43.

25. Kwon SH, Ahn IS, Kim SO, Kong CS, Chung HY, Do MS, et al. Antiobesity and hypolipidemic effects of black soybean anthocyanins. JMed Food. 2007;10(3):552-6.

26. Shamsi F, Asgari S, Rafieian M, Kazemi S, Adelnia A. Effects of Cornus Mas L. on Blood Glucose, Insulin and Histopathology of Pancreas in Alloxan-Induced Diabetic Rat. J Isfahan Med School. 2011;29(147):929-38.

27. Rasoulian H, Shahryar HA, Abbaspour R, Lotfi H. Effects of dietary inclusion of cornelian cherry (Cornus mas L.) fruit on body weight, insulin level and glycemic status of hamsters. PakJ Biol Sci. 2012;15(11):547-50.

28. Geetha JP, Srikrishna R. Role of red blood cell distribution width (RDW) in thyroid dysfunction. Int J Biol Med Res. 2012;3(2):1476-8.

29. Faure P, Roussel AM, Richard MJ, Foulon T, Groslambert P, Hadjian A, et al. Effect of an acute zinc depletion on rat lipoprotein distribution and peroxidation. Biol Trace Elem Res. 1991;28(2):135-46.

30. Yakubu MT, Akanji MA, Oladiji AT. Haematological evaluation in male albino rats following chronic administration of aqueous extract of Fadogia agrestis stem. Pharmacog Mag. 2007;3:34.

31. Yakubu MT, Akanji MA, Oladiji AT. Alterations in serum lipid profile of male rats by oral administration of aqueous extract of Fadogia argrestis stem. Res J Med Plant. 2008;2:66-73.

32. Yakubu MT, Lawal M, Akanji MA, Bilbis.. Evaluation of selected parameters of rat Liver and kidney function following repeated administration of yohimbine. Biochemistry. 2003;15:50-6.

33. Vagdatli E, Gounari E, Lazaridou E, Katsibourlia E, Tsikopoulou F, Labrianou I. Platelet distribution width: a simple, practical and specific marker of activation of coagulation. Hippokratia. 2010;14(1):28-32.

34. Salonen JT. Antioxidants and platelets. Ann Med. 1989;21(1):59-62.

35. Sobotkova A, Masova-Chrastinova L, Suttnar J, Stikarova J, Majek P, Reicheltova Z, et al. Antioxidants change platelet responses to various stimulating events. Free Radic Biol Med. 2009;47(12):1707-14.

36. Pignatelli P, Di Santo S, Buchetti B, Sanguigni V, Brunelli A, Violi F Polyphenols enhance platelet nitric oxide by inhibiting protein kinase C-dependent NADPH oxidase activation: effect on platelet recruitment. FASEB J. 2006;20(8):1082-9.

37. Rechner AR, Kroner C. Anthocyanins and colonic metabolites of dietary polyphenols inhibit platelet function. Thromb Res. 2005;116(4):327-34

38. Mallika V, Goswami B, Rajappa M. Atherosclerosis pathophysiology and the role of novel risk factors: a clinicobiochemical perspective. Angiology. 2007;58(5):513-22.

39. Pitocco D, Zaccardi F, Di Stasio E, Romitelli F, Santini SA, Zuppi C, et al. Oxidative stress, nitric oxide, and diabetes. Rev Diabet Stud. 2010;7(1):15-25.

40. Langer HF, Bigalke B, Seizer P, Stellos K, Fateh-Moghadam S, Gawaz M. Interaction of platelets and inflammatory endothelium in the development and progression of coronary artery disease. Semin Thromb Hemost. 2010;36(2):131-8.

41. Bjordal JM, Ljunggren AE, Klovning A, Slordal L. Non-steroidal antiinflammatory drugs, including cyclo-oxygenase-2 inhibitors, in osteoarthritic knee pain: meta-analysis of randomised placebo controlled trials. BMJ. 2004;329(7478):1317.

42. Whitehouse MW. Prostanoids as friends, not foes: further evidence from the interference by cycloxygenase-inhibitory drugs when in ducing tolerance to experimental arthritigens in rats. Inflammopharmacology. 2005;12(5-6):481-92.

43. Wedi B, Straede J, Wieland B, Kapp A. Eosinophil apoptosis is mediated by stimulators of cellular oxidative metabolisms and inhibited by antioxidants: involvement of a thiol-sensitive redox regulation in eosinophil cell death. Blood. 1999;94(7):2365-73.

44. Kohnen S, Franck T, Van Antwerpen P, Boudjeltia KZ, MouithysMickalad A, Deby C, et al. Resveratrol inhibits the activity of equine neutrophil myeloperoxidase by a direct interaction with the enzyme. J Agric Food Chem. 2007;55(20):8080-7.

45. Belge Kurutas E, Cetinkaya A, Bulbuloglu E, Kantarceken B. Effects of Antioxidant Therapy on Leukocyte Myeloperoxidase and $\mathrm{Cu}$ Zn-Superoxide Dismutase and Plasma Malondialdehyde Levels in Experimental colitis. Mediators Inflamm. 2005;6:390-4. 